\title{
Nanotechnologies for the restoration of alum-treated archaeological wood
}

\author{
Fabrizio Andriulo ${ }^{1} \cdot$ Susan Braovac $^{2} \cdot$ Hartmut Kutzke $^{2} \cdot$ Rodorico Giorgi $^{1}$ • \\ Piero Baglioni ${ }^{1}$
}

Received: 20 July 2015/ Accepted: 17 February 2016/Published online: 9 March 2016

(C) Springer-Verlag Berlin Heidelberg 2016

\begin{abstract}
The project Saving Oseberg is funded by the Norwegian State with the aim to preserve the Viking Age wooden objects from the Oseberg burial mound. They were excavated in 1904 near Tønsberg, Norway, and many have been treated in the past with alum salts $\left(\mathrm{KAl}\left(\mathrm{SO}_{4}\right)_{2} \cdot 12 \mathrm{H}_{2} \mathrm{O}\right)$. Alum was widely used during the early 1900 s as a treatment for archaeological wood to prevent shrinkage and impart strength. In the 1990s, conservators observed an alarming condition of the objects. Initial investigations showed that the alum treatment has initiated a slow but ongoing deterioration process, attacking the wood for over 100 years. Today, the artefacts are highly acidic and have significantly reduced mechanical strength. In the last decade, the use of nonaqueous alkaline nanoparticle dispersions has provided successful results for the protection of cellulose-based materials. Alum-treated archaeological wood samples from Oseberg, with a $\mathrm{pH} \leq 2$, have been treated with alkaline nanoparticle dispersions, and the effects of the treatment have been evaluated by thermal analysis (TGDTG), infrared spectroscopy (ATR-FTIR) and X-ray microtomography (micro-CT) analyses. In this contribution, the preliminary results will be presented.
\end{abstract}

Rodorico Giorgi

rodorico.giorgi@unifi.it

1 Department of Chemistry Ugo Schiff and CSGI, University of Florence, Via della Lastruccia 3, Sesto Fiorentino, 50019 Florence, Italy

2 Museum of Cultural History, University of Oslo, Postbox 6762 St. Olavs plass, 0130 Oslo, Norway

\section{Introduction}

The Oseberg finds, a selection of which is on display at the Viking Ship Museum in Oslo, Norway, represent a unique collection of Viking Age objects. The objects-many of which are made of wood-were excavated in 1904 from a ship burial constructed for two important women in 834 AD [1]. Object types include those used in religious ceremonies as well as in everyday life, and many bear intricate carvings [2].

The objects were waterlogged and highly fragmented upon recovery. Some wood types were so well preservedsuch as the oak from the Oseberg ship-that conservation treatment was not required before drying; other objects, however, many of which were made of diffuse porous hardwoods-such as the ceremonial sleds-were highly degraded and required stabilization before drying could take place. The method used to conserve these objects involved immersion in hot $\left(\mathrm{ca} 90^{\circ} \mathrm{C}\right)$, concentrated solutions of alum salts $\left(\mathrm{KAl}\left(\mathrm{SO}_{4}\right)_{2} \cdot 12 \mathrm{H}_{2} \mathrm{O}\right.$, aluminium potassium sulphate dodecahydrate). This treatment both strengthened and maintained the shape of the fragments: the salt replaced the water in the wood cells, and when removed from the hot bath the salt recrystallized immediately upon cooling. Before reconstruction into whole objects, fragments were impregnated with linseed oil and then pieced together using metal screws, pins, fills and modern wood. The reconstructed object was finally varnished. Fragments which were not reconstructed into objects are in the museum stores and may or may not contain linseed oil.

Although the alum method was mainly used in Scandinavia, it gained popularity in other parts of the world and was in use from the mid-nineteenth century to the 1960s, when it gradually was replaced by, for example, treatments 
using polyethylene glycol. After ca 1910, glycerol became a common addition to the alum treatment, which significantly increased the hygroscopicity of the treated wood relative to wood treated only with alum [3]. Thus, thousands of objects have been conserved with alum and alum/ glycerol during the period the treatment was in active use.

Today, the majority of the alum-treated objects are in poor condition: the wood is mechanically weakened and highly acidic $(\mathrm{pH} \leq 2)$. The source of chemical deterioration is attributed to the alum treatment itself, which generates significant amounts of sulphuric acid when heated [4]. It is also hypothesized that the presence of reactive transition metal ions, such as iron, enhances deterioration by oxidation, likely involving Fenton reactions [5].

As alum-treated wood is a highly complex material and little understood, the research project Saving Oseberg was established in 2013 to further elucidate the deterioration mechanisms of these archaeological wooden artefacts and to propose a conservation treatment to strengthen and chemically stabilize the wood. One of the research topics involves measures to deacidify the wood.

\subsection{Neutralization using nanoparticles}

One method to neutralize acidified wood involves surface applications of poultices with sodium bicarbonate solution. This method was used on the seventeenth-century Swedish warship Vasa, which temporarily increased the surface $\mathrm{pH}$ to 9-10. However, the effect did not last as there was no alkaline reserve, such that $\mathrm{pH}$ gradually returned to acidic values over a short period of time [6]. Another treatment using ammonia vapours darkened the wood, and $\mathrm{pH}$ was difficult to control [7]. Strong alkali could be harmful to the residual cellulose in wood [8].

Another potential method for the deacidification of acidic wood is the application of non-aqueous dispersions of nanoparticles, mainly $\mathrm{Ca}(\mathrm{OH})_{2}$, as proposed by the Department of Chemistry \& CSGI Consortium at the University of Florence [6]. The size of the nanoparticles used in this case ranges from 80 to $220 \mathrm{~nm}$ for $\mathrm{Ca}(\mathrm{OH})_{2}$. Alkaline earth metal hydroxide nanoparticles dispersions have demonstrated to be efficient for the preservation of cellulose-based artefacts, providing a stable neutral environment and, if present in excess, turning into mild alkaline species [9]. New formulations tailored for specific conservation issues have been recently obtained via a solvothermal reaction, starting from bulk metal to shortchain alcohols. Using this synthetic procedure, stable and highly concentrated calcium hydroxide nanoparticles dispersions may be obtained.

This method, also used to neutralize acidic paper and canvas, was applied to the Vasa ship $[6,10]$. Nanoparticle penetration inside the wood bulk is effected through a non-aqueous solvent, such as 2-propanol, which has a lower surface tension and is less viscous than water. Furthermore, when the nanoparticles have penetrated into the fibres, hydroxyl groups are released. In this way, it is possible to neutralize the acidity of the treated wood, and the alkaline reserve is expected to grant long-term protection to wood. Experiments performed at CSGI showed that archaeological wood treated with nanoparticles exhibited $\mathrm{pH}$ values granting long-lasting protection [1113]. Furthermore, differential thermogravimetric analysis (DTG) carried out on wood samples treated with nanoparticles from Vasa has shown that nanoparticles increased the resistance of wood towards thermal degradation. That is, results showed that the pyrolysis temperature of cellulose increased relative to that of the untreated degraded wood.

Given its potential, this method can be used to neutralize the acidity of the alum-treated Oseberg finds. The deacidification efficacy was assessed by $\mathrm{pH}$, DTG analysis, infrared spectroscopy (ATR-FTIR) and X-ray microtomography (micro-CT) measurements.

\section{Materials and methods}

\subsection{Chemicals}

Absolute ethanol (99.9\% Fluka) and metallic granular calcium (99\% Sigma Aldrich) were used for nanoparticle synthesis. Sulphuric acid (96\% Carlo Erba) was used for the acidification of wood samples. Alum (potassium aluminium sulphate dodecahydrate, $98 \%$ Sigma Aldrich) and glycerol (99.5\% Sigma Aldrich) were used to treat samples.

\subsection{Sample description}

The samples used in this study included recently excavated waterlogged archaeological wood (both softwood and hardwood), alum-treated archaeological wood from the Oseberg find and sound oak.

The hardwood samples were excavated in 2005 and stored in water. They were radiocarbon dated to 975-1150 AD (AaHW 0001, AaHW 0002) and were identified by light microscopy to be aspen (Populus spp.). The softwood archaeological samples (ApSW 0003, ApSW 0004, ApSW 0005) were retrieved in the 1990s and stored in water. They were identified by light microscopy to be pine (Pinus spp.). In 2013, these samples were treated in a solution of 2 parts alum to 1 part water (w/w) heated to $90{ }^{\circ} \mathrm{C}$ for $24 \mathrm{~h}$. The archaeological samples were documented by X-radiography before and after the alum treatment (Fig. 1). 

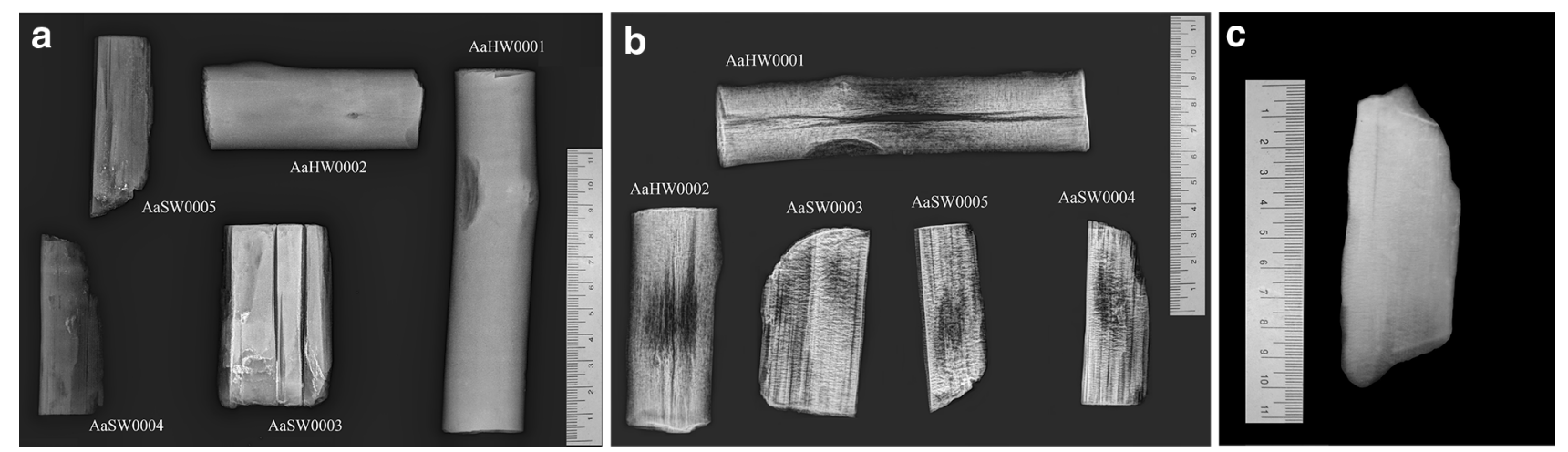

Fig. 1 X-rays of archaeological samples. Archaeological samples before treatment with alum (in the waterlogged state) (a) and after treatment with alum (b); alum-treated wood from Oseberg (c)

The sample from Oseberg was treated with alum without the addition of linseed oil (cat. no. C55000/229-232). It was classified as diffuse porous, since it could not be identified further due to its high degree of deterioration. An overview of samples is given in Table 1.

\subsection{Nanoparticle preparation}

Calcium hydroxide nanoparticles were synthesized, as reported in the literature [9] in an autoclave system working at high temperature and pressure, via a solvothermal process that can be described as a two-step reaction. In the first step of the synthesis, calcium metal is oxidized by short-chain alcohol, in this case ethanol, leading to the production of the corresponding alkoxide. The subsequent hydrolysis of this compound generates colloidal calcium hydroxide, which is dispersed in the solvent for the application.

\subsection{Wood deacidification}

Each sample was treated with nanoparticles dispersed in ethanol at a concentration of $5 \mathrm{~g} / \mathrm{L}$. The treatments were applied by directly dripping the solution onto the sample surface using a syringe, to wet them as homogeneously as possible, until complete saturation. The treated samples were then left to dry in a small chamber maintained at $50 \% \mathrm{RH}$ and $21{ }^{\circ} \mathrm{C}$ for 13 days.

Table 1 Sample overview

\begin{tabular}{ll}
\hline Sample name & Treatment \\
\hline AaH0001, AaHW0002 & Archaeological aspen, alum- \\
& treated 2013 \\
ApSW0003, ApSW 0004, & Archaeological pine, alum-treated \\
ApSW0005 & 2013 \\
Oseberg (C55000/229-232) & Diffuse porous. Alum-treated early \\
& 1900 s \\
\hline
\end{tabular}

A solution of glycerol and water was adjusted to a specific gravity (SG) of 1.204 to maintain the chamber equilibrium RH at $50 \%$, based on Eq. (1) [14].

$\mathrm{SG}=[-0.189(\mathrm{RH})+19.9]^{0.0806}$

\subsection{Measurement of wood $\mathrm{pH}$}

Alum solutions which have not been heated exhibit $\mathrm{pH}$ levels between 3.5 and 4 [4]. Solutions which have been heated to the temperature used in the alum treatment $\left(90^{\circ} \mathrm{C}\right)$ have a $\mathrm{pH}$ of about 2 after cooling [4]. Thus, one source of the high acidity measured in alumtreated wood $(\mathrm{pH} \leq 2)$ originated from the original thermal treatment $\left(90{ }^{\circ} \mathrm{C}\right)$. This resulted in the formation of aluminium hydroxide compounds and sulphuric acid, shown by reaction (2) [4].

$$
\begin{aligned}
3 \mathrm{KAl}\left(\mathrm{SO}_{4}\right)_{2}+6 \mathrm{H}_{2} \mathrm{O} \rightarrow & \mathrm{KAl}_{3}\left(\mathrm{SO}_{4}\right)_{2}(\mathrm{OH})_{6 \downarrow}+\mathrm{K}_{2} \mathrm{SO}_{4(\text { aq })} \\
& +3 \mathrm{H}_{2} \mathrm{SO}_{4(\mathrm{aq})}
\end{aligned}
$$

Potassium aluminium sulphate hydroxide (alunite) was identified in the precipitate. Considerable amounts are formed only after several hours of heating [4]. Moreover, according to Baty and Sinnott, aluminium ion $\mathrm{Al}^{3+}$ plays an important role as a catalyst in cellulose hydrolysis through coordination of aluminium by the glycosidic oxygen and $\mathrm{C}^{\prime}$ hydroxyl [15].

In order to verify the effects of deacidification treatments, it was necessary to measure the $\mathrm{pH}$ of wood samples before and after the treatment with nanoparticles. According to a standard TAPPI procedure (Technical Association of the Pulp and Paper Industries), $125 \mathrm{mg}$ of wood powder was suspended in $9 \mathrm{~mL}$ of distilled water (cold extraction method). The extracting suspension was kept at room temperature. The $\mathrm{pH}$ was measured after $1 \mathrm{~h}$ 
1. Between 50 and $350{ }^{\circ} \mathrm{C}$ (endothermic): dehydration in several steps

$\mathrm{KAl}\left(\mathrm{SO}_{4}\right)_{2} \cdot 12 \mathrm{H}_{2} \mathrm{O} \rightarrow \mathrm{KAl}\left(\mathrm{SO}_{4}\right)_{2}+12 \mathrm{H}_{2} \mathrm{O}$

2. Solid phasedecomposition

$\mathrm{KAl}\left(\mathrm{SO}_{4}\right)_{2} \rightarrow \mathrm{K}_{2} \mathrm{SO}_{4}+\mathrm{Al}_{2}\left(\mathrm{SO}_{4}\right)_{3}$

3. Between 750 and $950^{\circ} \mathrm{C}$ : decomposition of $\mathrm{Al}_{2}\left(\mathrm{SO}_{4}\right)_{3}\left(3 \mathrm{~mol}\right.$ of $\left.\mathrm{SO}_{3}\right)$

$\mathrm{Al}_{2}\left(\mathrm{SO}_{4}\right)_{3} \rightarrow \mathrm{Al}_{2} \mathrm{O}_{3}+3 \mathrm{SO}_{3}$

\section{At about $1100^{\circ} \mathrm{C}$ (endothermic): decomposition of $\mathrm{K}_{2} \mathrm{SO}_{4}$}

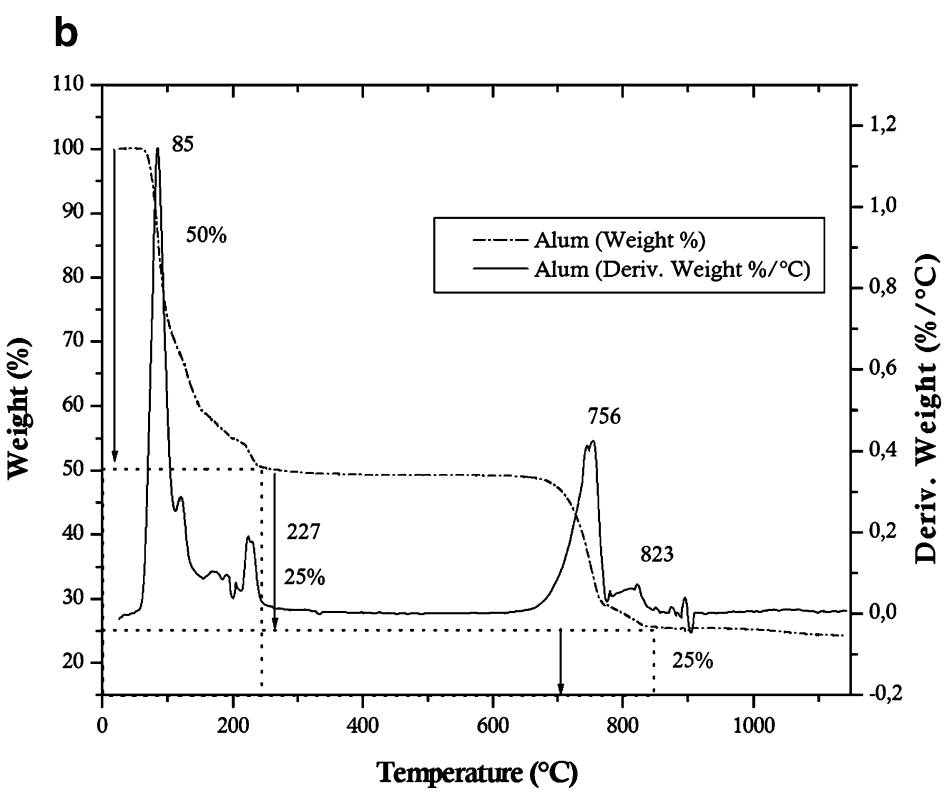

Fig. 2 Main thermal reactions of alum (left). TG and DTG curves of alum (right)

and $24 \mathrm{~h}$ using a digital $\mathrm{pH}$ meter Crison Basic 20 equipped with a glass electrode.

\subsection{Thermal analysis}

The differential thermogravimetric (DTG) curves of the samples were recorded in dynamic, non-isothermal conditions, using a TA SDT Q600 instrument. The experimental conditions were: temperature range: $30-1150{ }^{\circ} \mathrm{C}$; sample weight: $6-8 \mathrm{mg}$; heating rate: $10^{\circ} \mathrm{C} / \mathrm{min}$; $\mathrm{N}_{2}$ flow: $100 \mathrm{ml} /$ min. The error is $\pm 1.5^{\circ} \mathrm{C}$. Thermogravimetric analysis (TGA) was also carried out to investigate the percentages of mass loss as a function of the temperature.

\subsection{Infrared spectroscopy}

Samples were analysed by infrared spectroscopy, using Thermo Fisher FTIR spectrometer (Nicolet iS50) ATRFTIR unit, containing a ZnSe/diamond hybrid crystal, at a resolution of $4 \mathrm{~cm}^{-1}, 32$ scans per spectrum. Three spectra were taken from each sample before and after treatment with nanoparticles. The spectral range was $4000-400 \mathrm{~cm}^{-1}$.

\subsection{Microtomography}

Micro-CT is an experimental technique used to obtain three-dimensional microstructural information. In a typical experimental setup, the sample is placed on a rotating stage between an X-ray generator and a detector. For a specific exposure time, X-rays are attenuated proportionally to the material's density and reach the detector to form a shadow projection containing information about the microstructure. The sample is then rotated a fractional amount, and a second shadow projection is obtained from a slightly offset perspective. A $180^{\circ}$ rotation generates a sufficient set of such projections which are reconstructed into parallel microslices using a mathematical algorithm.

For the micro-CT imaging analysis, a SkyScan 1172 system was used at the CRIST center, Centro di Cristallografia Strutturale, of the University of Florence.

\section{Results and discussion}

Measurements of $\mathrm{pH}$ were performed on deacidified samples after 1 and $24 \mathrm{~h}$ from application; no significant changes were detected. The $\mathrm{pH}$ of untreated samples was found to be around 2.5-3, whereas after deacidification the $\mathrm{pH}$ of wood samples was raised to 5 , quite close to the original $\mathrm{pH}$ of fresh hardwood. After 13 days at $50 \% \mathrm{RH}$ of storage, deacidified wooden samples still maintain the same level of acidity. All samples treated with nanoparticles showed an increase in $\mathrm{pH}$ value of 2-3 units. After 1 month of the treatment with nanoparticles, $\mathrm{pH}$ values were still stable.

The effects of deacidification treatment on degraded wood were also monitored by DTG. The relevant content of alum within wood porosity has required an accurate analysis of all the thermal events involving this material, in order to facilitate the interpretation of thermal analysis 
Fig. 3 Comparison between DTG curves of Fresh oak and AaHW 0001 (alum-treated archaeological aspen). The DTG curve of fresh oak shows main thermal degradation peaks of wood in good condition (left). TG and DTG curves of sample AaHW 0001 (right)
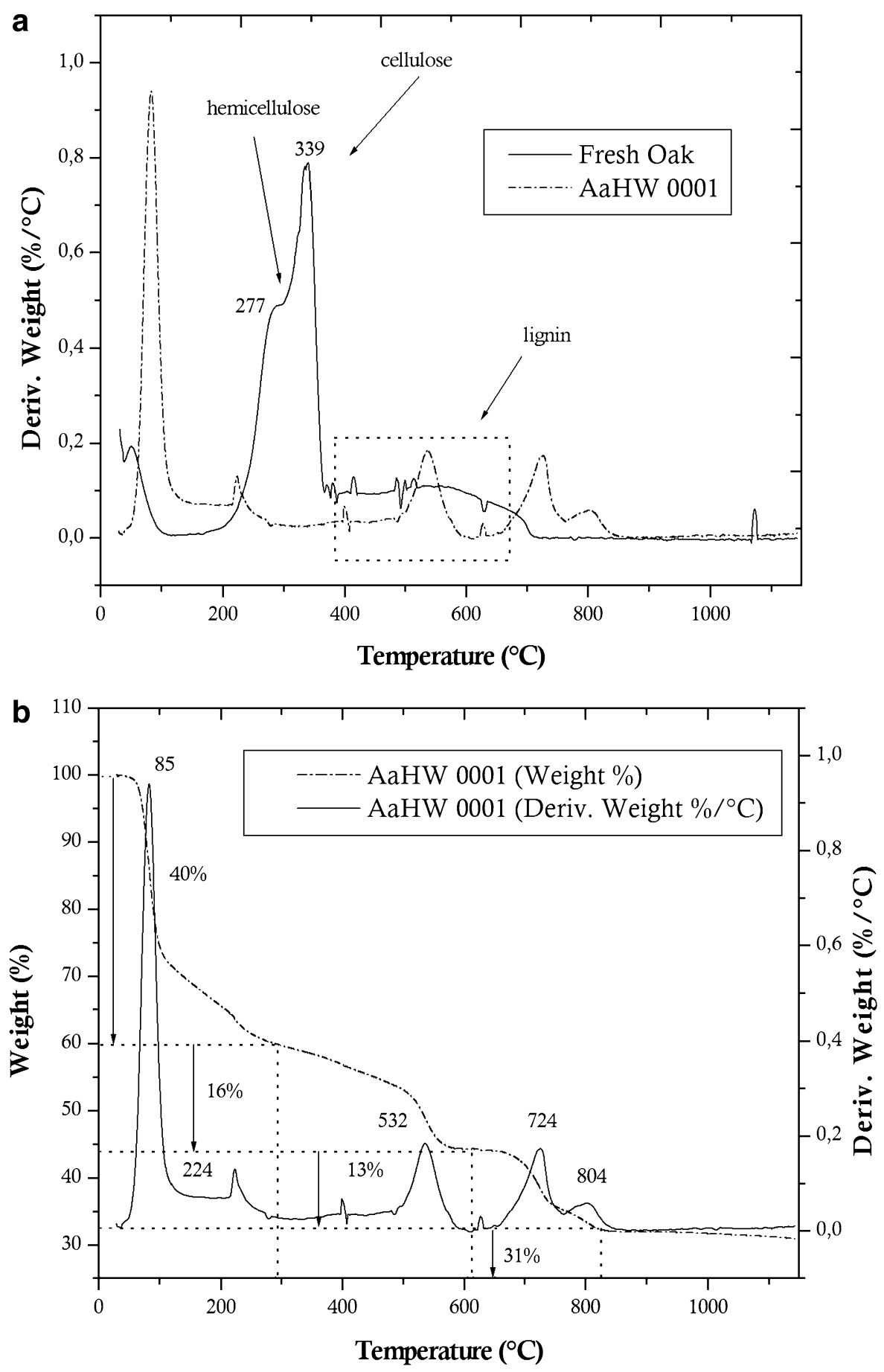

Table 2 Weight $\%$ of main products involved in the thermal degradation of AaHW0001

\begin{tabular}{lllllll}
\hline & Initial weight $(\mathrm{mg})$ & Final weight $(\mathrm{mg})$ & Water content & Lignin content & $\mathrm{SO}_{3}{\mathrm{~mol} \mathrm{of} \mathrm{Al}_{2}\left(\mathrm{SO}_{4}\right)_{3}}_{\mathrm{Al}_{2} \mathrm{O}_{3}}$ \\
\hline AaHW 0001 & 8.962 & 2.769 & $40 \%$ & $16 \%$ & $13 \%$ & $31 \%$ \\
\hline
\end{tabular}

data. The characteristic thermal curve for alum is shown in Fig. 2, and the main thermal reactions involved are highlighted [16]. As already reported in the literature [9], the pyrolysis temperature of cellulose $\left(T_{\mathrm{p}}\right)$ can be used for monitoring the efficacy of deacidification treatment, where it was shown that higher $T_{\mathrm{p}}$ values correspond to samples 

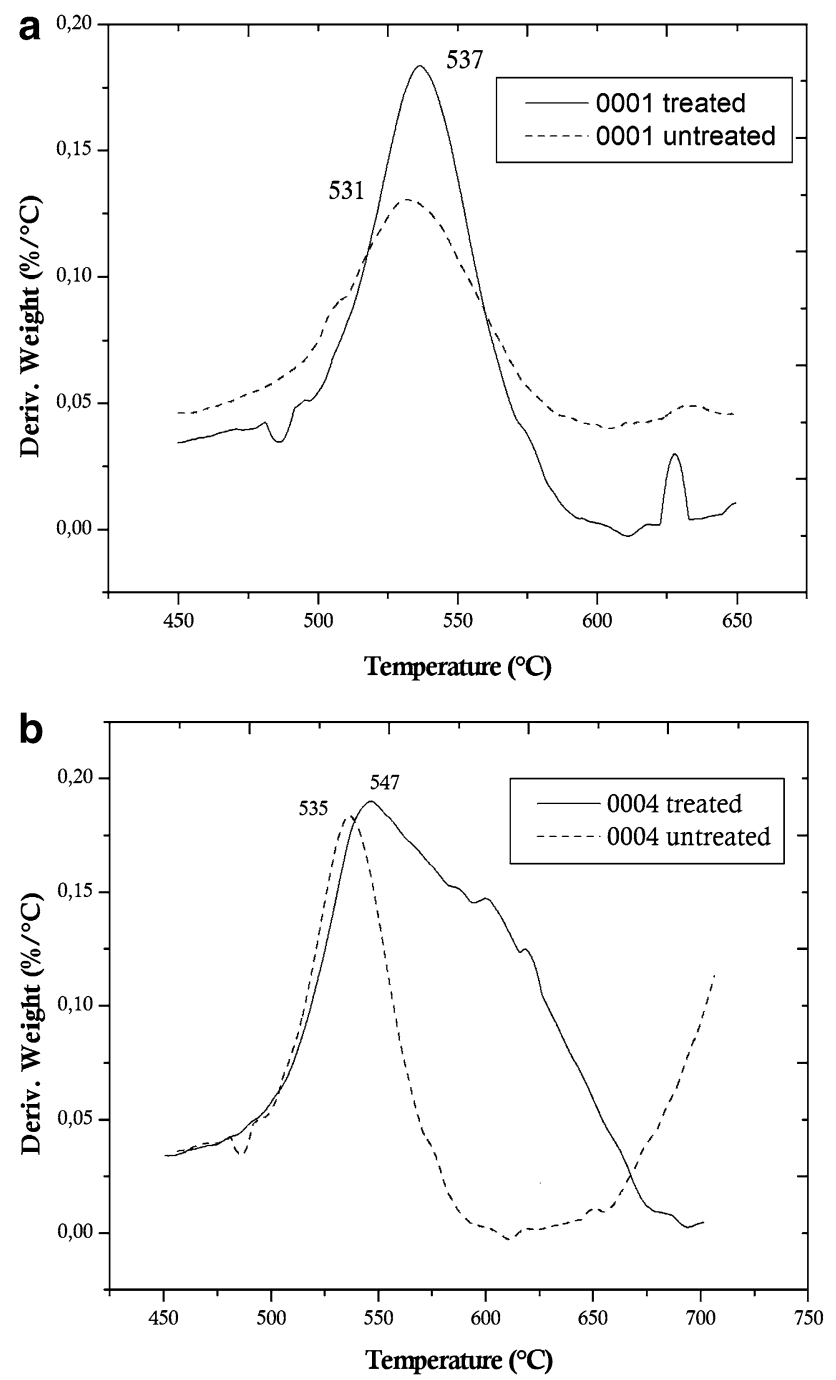

Fig. 4 Comparison between DTG curves of AaHW 0001 and AaHW 0001 samples before and after deacidification treatment (left). Comparison between DTG curves of ApSW 0004 and ApSW 0004 samples before and after deacidification treatment (right)

more resistant to thermal degradation in accordance with higher $\mathrm{pH}$ values [13]. Unfortunately, the wood samples in this study are highly degraded, and the signals associated with the pyrolysis of cellulose are negligible. The only thermal event that can be clearly seen in the derivative thermogravimetric curves is associated with the pyrolysis of lignin; the temperature corresponding to the maximum rate of lignin mass loss will be reported as $T_{1}$. The release of $\mathrm{CO}$ is characteristic of the last stages of pyrolysis at higher temperatures at around $400{ }^{\circ} \mathrm{C}$. The process of devolatilization of lignin is practically completed above $600{ }^{\circ} \mathrm{C}$. In Fig. 3, the thermal profile for the fresh oak sample and sample AaHW 0001 is reported. Table 2 shows the $\%$ weight of the main pyrolysis products evolved from AaHW 0001.
The archaeological samples (AaHW 0001, AaHW 0002, ApSW 0003, ApSW 0004, ApSW 0005) were characterized by DTG after the application of nanoparticles. The deacidified samples showed a significant increase in $T_{1}$, with differences ranging from 6 to $12{ }^{\circ} \mathrm{C}$ when compared to the untreated wooden samples (see Fig. 4). The observed increase in $T_{1}$ can partly be explained as an effect of the introduction of calcium hydroxide nanoparticles within wood porosity. In fact, it has been hypothesized that the bivalent positive calcium ions from the deacidification treatment could also contribute to increase the resistance of treated wood to thermal degradation [17] due to the chelating complex formed with hydroxyl and methoxy groups of lignin.

The distribution of alkaline nanoparticles within the wooden samples porosity was investigated with micro-CTimaging. Two small splinters of wood ( $2 \mathrm{~mm}$ in size) were taken from AaHW 0001 and ApSW 0004 samples. Each splinter was mounted vertically on the SkyScan 1172 scanner sample chamber, for analysis with micro-CT imaging technique. Data were collected before and after the treatment with alkaline nanoparticles of $\mathrm{Ca}(\mathrm{OH})_{2}$ dispersed in ethanol (at concentration of $5 \mathrm{~g} / \mathrm{L}$ ). From cross sections and 3D reconstruction, the penetration of nanoparticles within the wood was evaluated. Figure 5a-d shows that alum (brighter areas in the pictures) is evenly distributed within wood, and apparently it fills almost all vessels. The darker areas represent the wood structure, mainly composed of lignin, as was demonstrated by DTG analyses. Denser white clusters, evidenced with boxes in the pictures, may be attributed, according to differences in attenuation, to alunite $\left(\mathrm{KAl}_{3}\left(\mathrm{SO}_{4}\right)_{2}(\mathrm{OH})_{6}\right)$, presumably formed, before the application, after the heating treatment of alum. Figure 5b, d shows images after treatment where brighter and less contrasted areas are clearly visible, indicating greater attenuation of the X-ray beam due to the presence of nanoparticles. In particular, it is quite evident that particles are mainly located at the surface. The pictures show a fair penetration with a large gradient from the surface to the inner part. This is an obvious consequence of the large amount of alum still filling the pores (white bright areas in the figures).

The analysis of FTIR spectra of alum-treated wood samples clearly shows that alum and wood presented overlapping bands in the region 1700-1500 and $1200-800 \mathrm{~cm}^{-1}$. The high level of degradation of wood is further confirmed by the lack of the characteristic peaks from cellulose and hemicelluloses, in particular, the signals at $898 \mathrm{~cm}^{-1}$ (C1 group frequency in cellulose + hemicellulose; $\mathrm{C}-\mathrm{H}$ deformation cellulose; glucose ring stretch, cellulose [18]), $1158 \mathrm{~cm}^{-1}$ (asymmetric CO-C vibration carbohydrate [19]), $1371 \mathrm{~cm}^{-1}$ (symmetric $\mathrm{C}-\mathrm{H}$ deformation carbohydrate $+\mathrm{C}-\mathrm{H}$ bending 

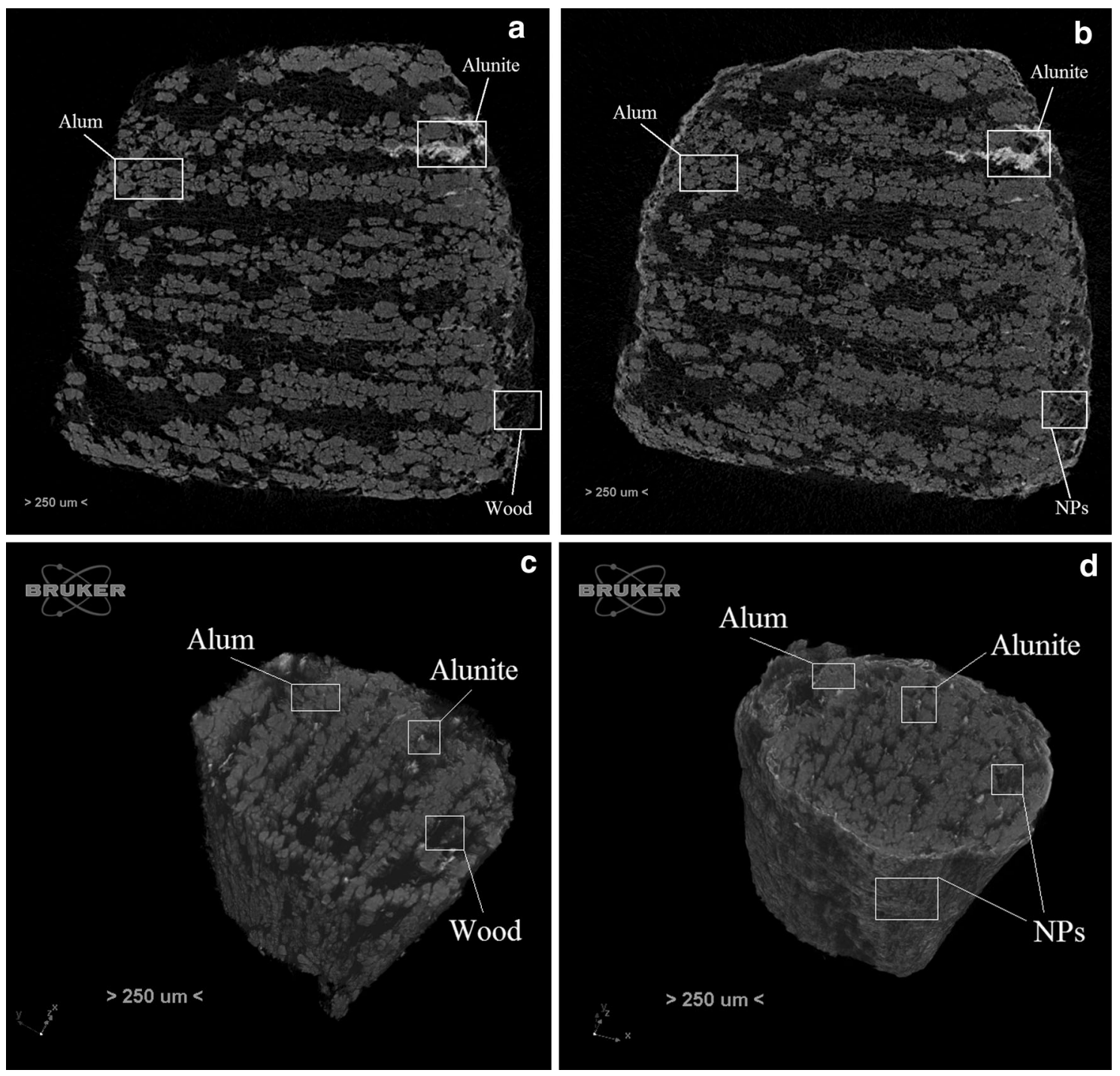

Fig. 5 Sample AaHW 0001 cross section before (a) and after deacidification treatment (b). 3D reconstruction of wooden splinter taken from AaHW 0001 sample before (c) and after deacidification treatment (d)

carbohydrate [20]) and $1738 \mathrm{~cm}^{-1}$ (COO stretch of ester from hemicellulose [20]). Despite the overlapping bands from alum and wood, aromatic skeletal vibration attributed to lignin at $1505 \mathrm{~cm}^{-1}$ [18] was observed. However, the presence of peak at $1713 \mathrm{~cm}^{-1}$ (assigned to carbonyl stretching [18]) suggests that the lignin has been subjected to oxidation.

Figures 6 and 7 show that alkaline particles were capable of neutralizing most of the acidity in the alum-treated Oseberg sample (Fragment 1). Spectra from the Oseberg sample treated with nanoparticles show the presence of a band at $659 \mathrm{~cm}^{-1}$ that can be attributed to antisymmetric bending vibration mode of $\mathrm{SO}_{4}{ }^{2-}$ [21], which results from the neutralization reaction of sulphuric acid with alkaline nanoparticles. The neutralization reaction is fast and complete, and this accounts for the lack of signals from calcium hydroxide at $3621 \mathrm{~cm}^{-1}$.

Calcium hydroxide also reacts spontaneously with $\mathrm{CO}_{2}$ forming $\mathrm{CaCO}_{3}$, as evidenced by FTIR analysis in Fig. 8, where the asymmetric stretching of $\mathrm{CO}_{3}{ }^{2-}$ at $1409 \mathrm{~cm}^{-1}$ is shown for treated sample ApSW 0004. According to FTIR data, a complete carbonation, at room conditions, has occurred in 2 weeks.

In principle, the application of alkaline nanoparticles can be repeated with the purpose to further increase the $\mathrm{pH}$ of the Oseberg wooden samples. A slight excess of particles may provide the artefact with an alkaline buffer against recurring acidity [22]. 


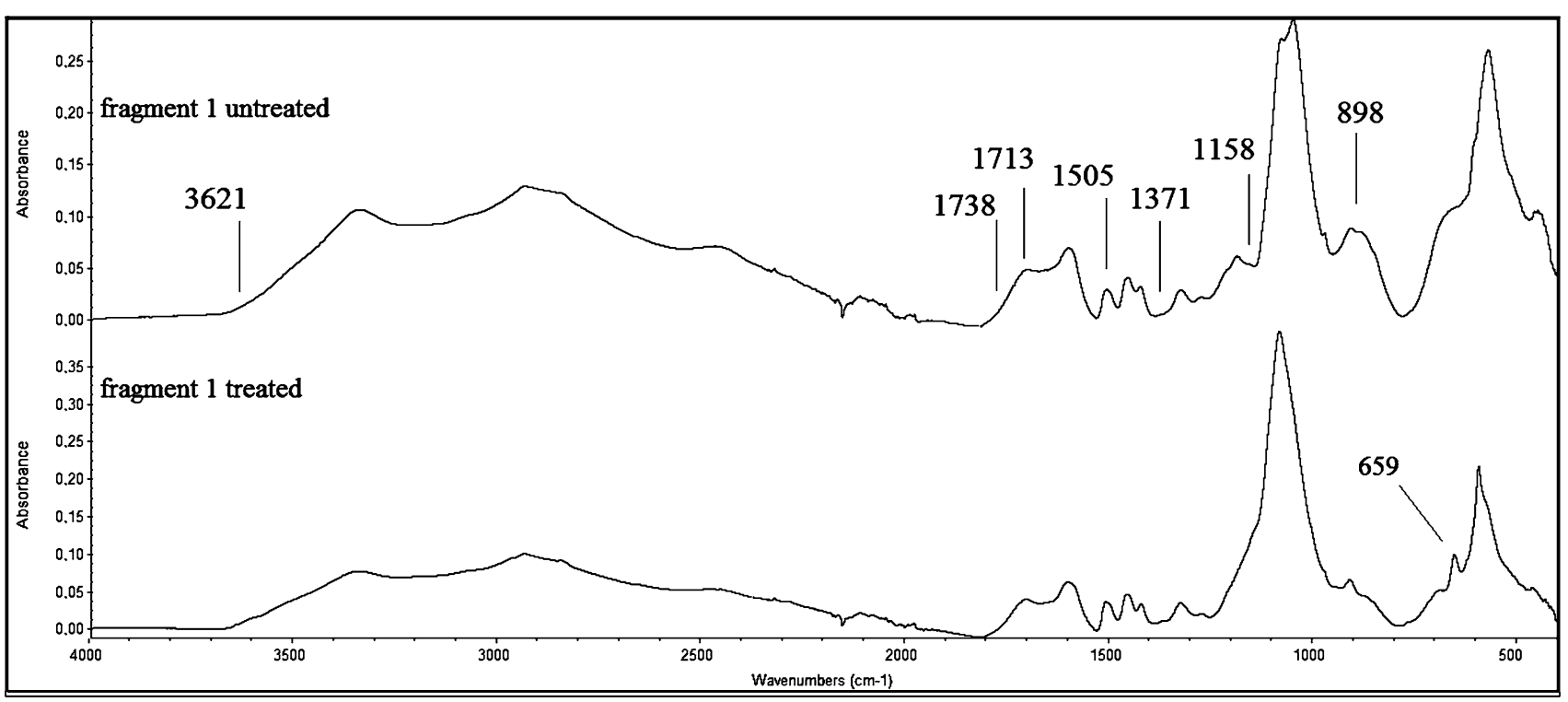

Fig. 6 Infrared spectra of the region $4000-400 \mathrm{~cm}^{-1}$ of the Oseberg sample (fragment 1) before and after deacidification treatment. Lacking of peaks attributed to carbohydrates modes explains the high grade of degradation of the sample

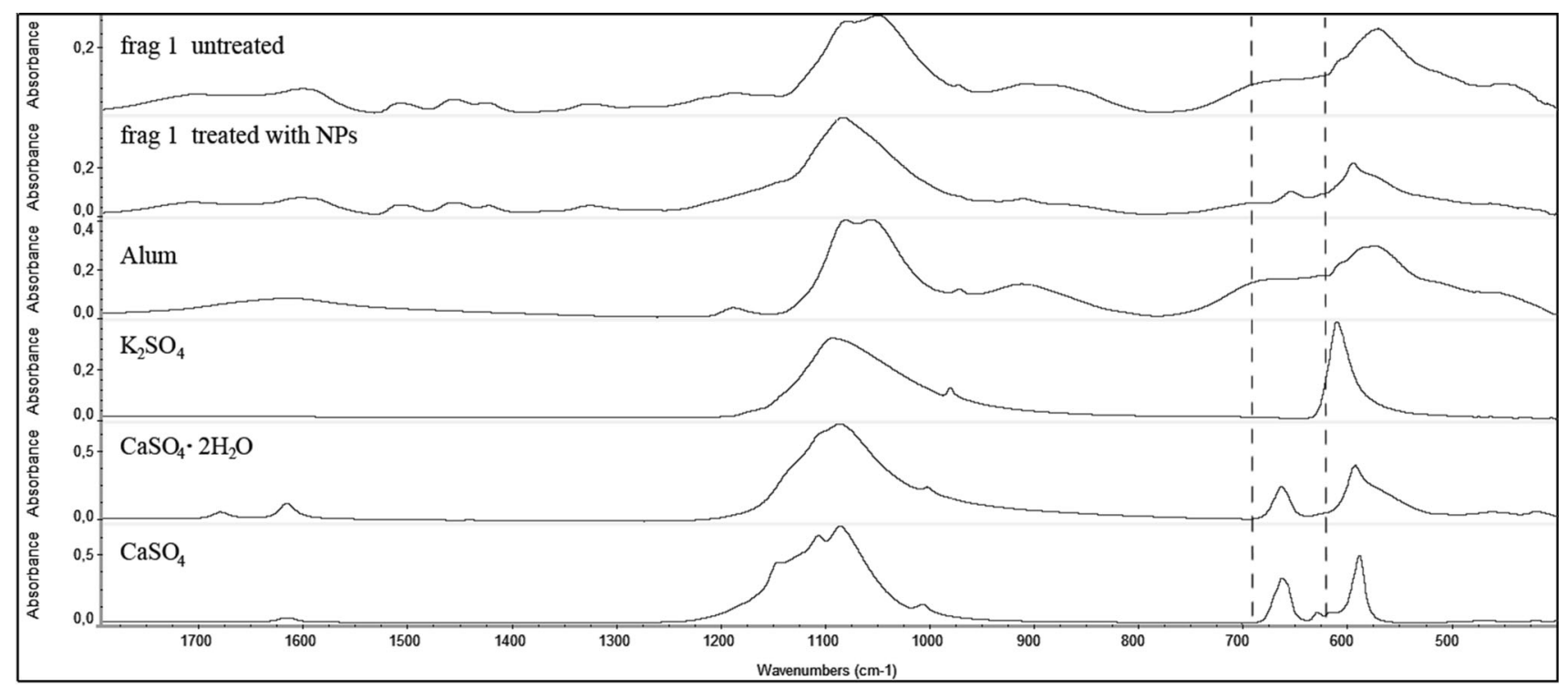

Fig. 7 Infrared spectra of the fingerprint region $\left(1800-400 \mathrm{~cm}^{-1}\right)$ of Oseberg sample (fragment 1) before and after deacidification treatment, Alum, $\mathrm{K}_{2} \mathrm{SO}_{4}, \mathrm{CaSO}_{4} \cdot 2 \mathrm{H}_{2} \mathrm{O}$ and $\mathrm{CaSO}_{4}$. Treated fragment 1 shows the presence of calcium sulphate anhydrous (Anhydrite)

\section{Conclusion}

The application of alkaline nanoparticles dispersed in alcohol on some selected archaeological wooden finds has produced a $\mathrm{pH}$ increase (2-3 units) in line with the expectations. However, the investigations carried out on the archaeological samples have shown a dramatic scenario, where cellulose is almost lost and the wood samples are composed of lignin and alum only. The penetration of particles is partially inhibited by alum that is filling the pores. However, final $\mathrm{pH}$ at $5-5.5$ that is quite close to the original $\mathrm{pH}$ of hardwood may provide some benefit to the selected samples, as evidenced by thermal analysis. This study has provided important information about the composition of archaeological alum-treated wood and about the distribution of alum inside. At the moment, alum is playing a key role in the mechanical stabilization of wood; however, it is also the main source of acidity, and for that reason, it is mandatory to remove as much alum as possible, in order to allow a deeper and more homogeneous 


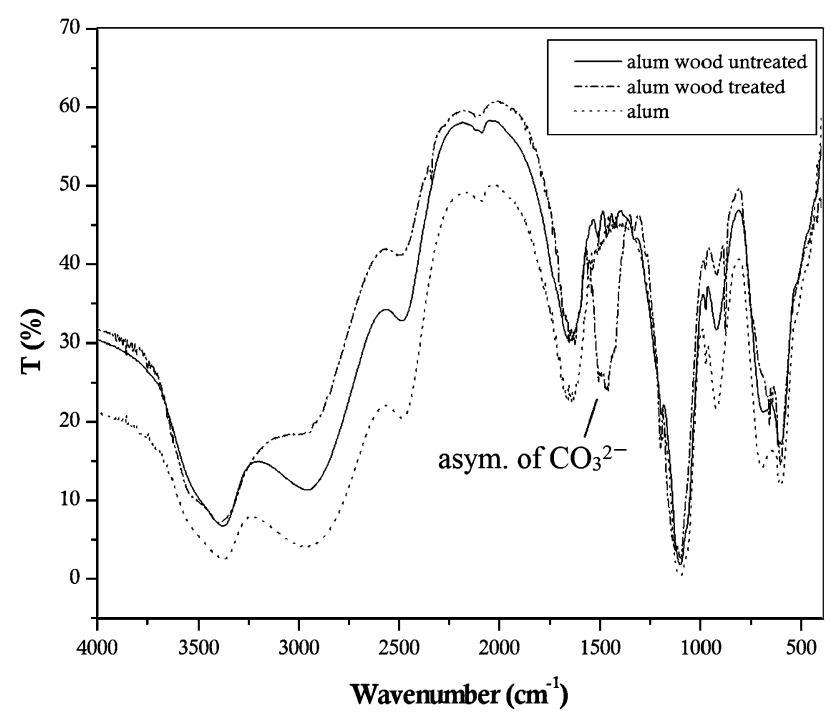

Fig. 8 Infrared spectra of the region $4000-400 \mathrm{~cm}^{-1}$ of alum and ApSW 0004 sample. Infrared spectra of wooden sample were acquired before and after treatment with slight excess of nanoparticles

penetration of alkaline nanoparticles and possibly to facilitate the injection of hybrid organic/inorganic materials, such as alkaline particles with functionalized cellulose, to produce a more compatible strengthening network within the wood porosity.

Acknowledgments F.A., R.G. and P.B. wish to thank Dr. Francesca Loglio and Dr. Samuele Ciattini of the CRIST center, Centro di Cristallografia Strutturale, University of Florence, for X-ray microtomography analysis. CSGI, Center for Colloid and Surface Science, is also gratefully acknowledged for financial support. This work was undertaken by Saving Oseberg, a research project funded by the Norwegian State and the University of Oslo.

\section{References}

1. N. Bonde, A.E. Christensen, Antiquity 67, 575 (1993)

2. A.W. Brøgger, H. Shetelig, H. Falk, Osebergfundet (Distribuert ved Universitetets Oldsaksamling, Oslo, 1917)

3. B.B. Christensen, Studies in Museum Technology 1: The Conservation of Waterlogged Wood in the National Museum of Denmark (The National Museum of Denmark, Copenhagen, 1970)

4. S. Braovac, H. Kutzke, J. Cult. Herit. 13, 203 (2012)

5. G. Almkvist, I. Persson, Holzforschung 62(6), 694 (2008)

6. R. Giorgi, D. Chelazzi, P. Baglioni, Langmuir 21, 10743 (2005)

7. Y. Fors, M. Sandstrom, Chem. Soc. Rev. 35, 399 (2006)

8. P. Calvini, V. Grosso, M. Hey, L. Rossi, L. Santucci, Pap. Conserv. 12, 35 (1988)

9. G. Poggi, N. Toccafondi, L.N. Melita, J.C. Knowles, L. Bozec, R. Giorgi, P. Baglioni, Appl. Phys. A 114, 685 (2014)

10. P. Baglioni, D. Chelazzi, Nanoscience for the Conservation of Works of Art (RSC Publishing, London, 2013)

11. P. Baglioni, R. Giorgi, Soft Matter 2, 293 (2006)

12. P. Baglioni, D. Chelazzi, R. Giorgi, G. Poggi, in Encyclopedia of Surface and Colloid Science, 2nd edn., ed. by P. Somasundaran (Taylor \& Francis, New York, 2012), pp. 1-16

13. D. Chelazzi, R. Giorgi, P. Baglioni, Macromol. Symp. 238, 30 (2006)

14. C.F. Forney, D.G. Brandl, HortTechnology 2, 52 (1992)

15. J.W. Baty, W. Minter, S. Yong Lee, Book Pap. Group Annu. 29, 113 (2010)

16. M. Földvári, in Handbook of Thermogravimetric System of Minerals and its Use in Geological Practice, Occasional Papers of the Geological Institute of Hungary, vol 213 (Geological Institute of Hungary, Budapest, 2011), pp. 216-217

17. H.A. Shnawa, Mater. Sci. Appl. 2, 692 (2011)

18. K.K. Pandey, J. Appl. Polym. Sci. 71, 1969 (1999)

19. K.K. Pandey, A.J. Pitman, Int. Biodeterior. Biodegradation 52, 151 (2003)

20. B. Mohebby, Int. Biodeterior. Biodegradation 55, 247 (2005)

21. Y. Liu, A. Wang, J.J. Freeman, in Raman, MIR, and NIR Spectroscopic study of calcium sulfates: gypsum, bassanite, and anhydrite, 40th Lunar and Planetary Science Conference (2009)

22. F.A. Andersen, L. Brečević, Acta Chem. Scand. 45, 1018 (1991) 